Ann. Geophys., 26, 395-400, 2008

www.ann-geophys.net/26/395/2008/

(C) European Geosciences Union 2008

\title{
Surface buoyancy flux in Bay of Bengal and Arabian Sea
}

\author{
G. Anitha ${ }^{1}$, M. Ravichandran ${ }^{1}$, and R. Sayanna ${ }^{2}$ \\ ${ }^{1}$ Indian National Centre for Ocean Information Services, Hyderabad, India \\ ${ }^{2}$ Osmania University, Hyderabad, India
}

Received: 19 June 2006 - Revised: 7 December 2007 - Accepted: 19 December 2007 - Published: 26 March 2008

\begin{abstract}
The seasonal variation of thermal, haline, net surface buoyancy flux, the Monin-Obukhov length (M-O length, $L)$ and stability parameter, i.e. the ratio of M-O length to mixed layer depth $(h)$ were studied in the Bay of Bengal (BoB) and the Arabian Sea (AS) for the years 2003 and 2004 using Argo temperature and salinity profiles. The relative quantitative influence of winds to surface buoyancy and the applicability of scaling mixed layer using M-O length in BoB and AS was brought out. Rotation and light penetration modify the mixed layer depth from M-O length during shoaling in spring giving $L / h<1$.
\end{abstract}

Keywords. Meteorology and atmospheric dynamics (Turbulences) - Oceanography: physical (Air-sea interactions; Upper ocean processes)

\section{Introduction}

The Arabian Sea (AS) and Bay of Bengal (BoB) are two basins in the north Indian Ocean that are influenced by seasonally reversing monsoonal wind forcing. The freshwater forcing between these two basins is contrasting. Precipitation (P) exceeds evaporation (E) in the Bay, whereas evaporation exceeds precipitation in the AS. The freshness of $\mathrm{BoB}$ is due to excess precipitation over evaporation and due to large amounts of river discharge into the Bay. Hence the surface layer in the Bay is much fresher than that in the Arabian Sea. Very few studies exist on the quantitative role of thermal, haline (due to fresh water content) and net buoyancy against the mechanical mixing in Bay of Bengal and Arabian Sea using observations. Weller et al. (2002) explored the relative importance of wind mixing and surface buoyancy forcing in mixed-layer deepening in the AS during October 1994 to October 1995 and found that wind mixing

Correspondence to: G. Anitha

(anitha@incois.gov.in) is the primary driver of mixed-layer deepening during the summer monsoon (June-September) while convective deepening driven by surface buoyancy fluxes is more important during the winter monsoon (December-February). Shenoi et al. (2002), using a model as well as Levitus and Boyer climatology have shown that the energy available for mixing the upper $50 \mathrm{~m}$ is greater by an order of magnitude in the Arabian Sea than that in the Bay of Bengal during the summer monsoon. They also found that the energy required for mixing the top $50 \mathrm{~m}$ in the Bay of Bengal is about three times greater than that in the Arabian Sea. They concluded that the weaker winds over the Bay of Bengal are incapable of mixing the strongly stratified surface waters. By conducting different experiments using a 1-D model, Prasad (2004) concluded that humidity is the controlling factor rather than the salinity which is responsible for the buoyancy difference between the two basins. However, comparative studies of the depth of influence of wind stress versus buoyancy forcing and the applicability of M-O scaling in both the basins for the entire year using observations are not present. In this study we bring out quantitatively the role of freshwater, thermal and net surface buoyancy based on Argo and other observations and the applicability of M-O scaling during different seasons.

\section{Data and methods}

Argo floats are autonomous profiling floats with CTD sensors that measure temperature and salinity in the ocean as a function of depth. The details of the global profiling float project and its data communication are found in Argo Science Team (1998) and Ravichandran et al. (2004). The study region is Bay of Bengal and Arabian Sea. The area enclosed by $60 \mathrm{E}$ to $70 \mathrm{E}$ and $10 \mathrm{~N}$ to $19 \mathrm{~N}$ is considered to represent the central Arabian Sea and that enclosed by $85 \mathrm{E}$ to $95 \mathrm{E}$ and $10 \mathrm{~N}$ to $19 \mathrm{~N}$ to represent central Bay of Bengal. The temperature and salinity profiles from all the Argo floats falling in these

Published by Copernicus Publications on behalf of the European Geosciences Union. 


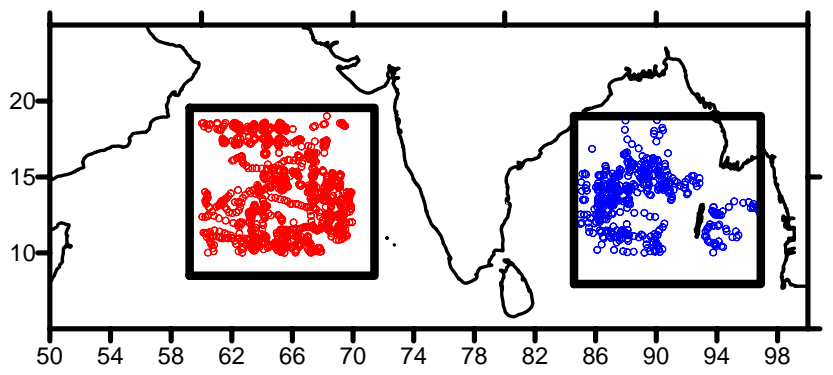

Fig. 1. Locations of Argo Float profiles in Bay of Bengal and Arabian Sea representative areas during 2003 and 2004.

regions during the years 2003 and 2004 are used to study the upper ocean. The temperature data measured by Argo floats at the standard depths are used to generate values at 1-m intervals following Borkowski and Goulet (1971). A total of 1088 profiles in AS and 470 profiles in BoB were analysed for the study. The representative regions and the profiles' locations are shown in Fig. 1.

We used the $0.25^{\circ} \times 0.25^{\circ}$ fields of wind parameters measured by Quickscat and $1^{\circ} \times 1^{\circ}$ precipitation from the Global Precipitation Climatology Project (GPCP) data set. The net heat flux is obtained from the Southampton Climatology Oceanography Centre (SOC) surface climatology, available at the website www.coaps.fsu.edu. A correlation coefficient of 0.641 is obtained for the SOC net heat flux with that of the WHOI mooring site observations. The SOC climatology monthly mean net heat flux (NHF) is found to be within $20 \mathrm{~W} / \mathrm{m}^{2}$ of the WHOI mooring in the Arabian Sea (Josey et al., 1999). The errors thus propagating into the derived parameters are computed using a differential method and the corresponding errors are depicted as error bars in the plots. Mixed layer depth (MLD) is defined as the deepest depth where the density is higher by $0.20 \mathrm{Kg} / \mathrm{m}^{3}$ from $10-\mathrm{m}$ depth. The net surface buoyancy $B_{o}$ is computed using

$B_{o}=B_{q}+B_{p}$

$B_{o}=\left(g \alpha Q_{o} /\left(\rho C_{p}\right)\right)+g \beta P S_{o}$,

where $B_{q}$ is thermal buoyancy, $B_{p}$ is haline (due to fresh water) buoyancy, $g$ is gravity, $Q_{0}$ is net heat flux, $\rho$ is ocean water density, $C_{p}$ is the specific heat of water, $S_{o}$ is surface salinity, $P$ is precipitation, $\alpha$ is the thermal co-efficient of expansion and $\beta$ is coefficient of haline contraction. The error propagated into the net buoyancy flux due to the error in NHF is computed to be $\pm 6.63 \times 10^{-9} \mathrm{~m}^{2} / \mathrm{s}^{3}$. The Monin-Obukhov length, $L$, is computed using the Argo temperature and salinity profile and quickscat wind data using the formulation

$L=-\left(U_{*}^{3} / \kappa B_{0}\right)$,

where Von Karman's constant is $\kappa=0.41$. Friction velocity $U_{*}^{3}$ is calculated from the surface wind-stress using

$U_{*}^{3}=\left(\tau_{0} / \rho\right)^{3 / 2}$, where $\tau_{0}$ is wind-stress and $\rho$ is ocean water density. For each month of the years 2003 and 2004, at all the locations of the Argo profiles obtained in a calendar month in the representative regions of $\mathrm{BoB}$ and $\mathrm{AS}$, the corresponding other parameters viz., GPCP precipitation, Quickscat winds and SOC-NHF are extracted. These parameters are extracted at the co-located time (calendar day average) and space (averaged over a $1^{\circ} \times 1^{\circ}$ latitude-longitude box for each profile) of the corresponding Argo temperature and salinity profile. The values for each parameter (temperature, salinity, density, mixed layer depth, precipitation and friction velocity) falling in a calendar month are averaged from which the buoyancy fluxes and M-O length are computed. Hence all the analysis is done on a monthly scale from February 2003 to December 2004.

\section{Discussion}

\subsection{Surface buoyancy flux}

Buoyancy flux through the surface helps determine the stability of the upper ocean. At the sea surface, surface warming (heat gain by the ocean) or precipitation tends to make the ocean surface more buoyant and contributes to stable conditions. Conversely, surface cooling or evaporation tends to make the ocean surface less buoyant and contributes to an increase in density of the surface water and so to a convectively unstable condition. The net surface buoyancy flux in both the basins is largest during summer monsoon months, i.e. June to September, and looks similar in pattern (Fig. 2a) with a lull during August (2003 and 2004 in AS and 2004 in $\mathrm{BoB})$. However, in $\mathrm{BoB}$, the net surface buoyancy continues to be large in fall, i.e. during late September and October, which is a manifestation of the large fresh water content. This is reasoned by observing the two components of buoyancy fluxes. During this part of the year the fresh water buoyancy is the major contributor, whereas the thermal component is minute and also almost equal in both the basins (Fig. 2a, b, c, d). This freshness of BoB is due to excess precipitation and heavy river discharge (the measured salinity by Argo float $S_{0}$ is due to both precipitation as well as river discharge). The net surface buoyancy flux in both BoB and AS is always positive except in December. In AS, few negative spikes in July-August and NovemberDecember for both 2003 and 2004 are observed when individual profile observations are examined (figure not shown). The net surface buoyancy is very high in BoB compared to AS throughout the two years, indicating a very highly stable upper ocean in BoB compared to AS. During the peak monsoon the magnitude of net surface buoyancy in BoB is more than $3 \times 10^{-7} \mathrm{~m}^{2} / \mathrm{s}^{3}\left(4.25 \times 10^{-7} \mathrm{~m}^{2} / \mathrm{s}^{3}\right.$ in July 2003 and $3.02 \times 10^{-7} \mathrm{~m}^{2} / \mathrm{s}^{3}$ in July 2004), whereas in AS it is around $1.1 \times 10^{-7} \mathrm{~m}^{2} / \mathrm{s}^{3}\left(1.18 \times 10^{-7} \mathrm{~m}^{2} / \mathrm{s}^{3}\right.$ in July 2003 and $1.86 \times 10^{-7} \mathrm{~m}^{2} / \mathrm{s}^{3}$ in July 2004) (Fig. 2a). A notable point 

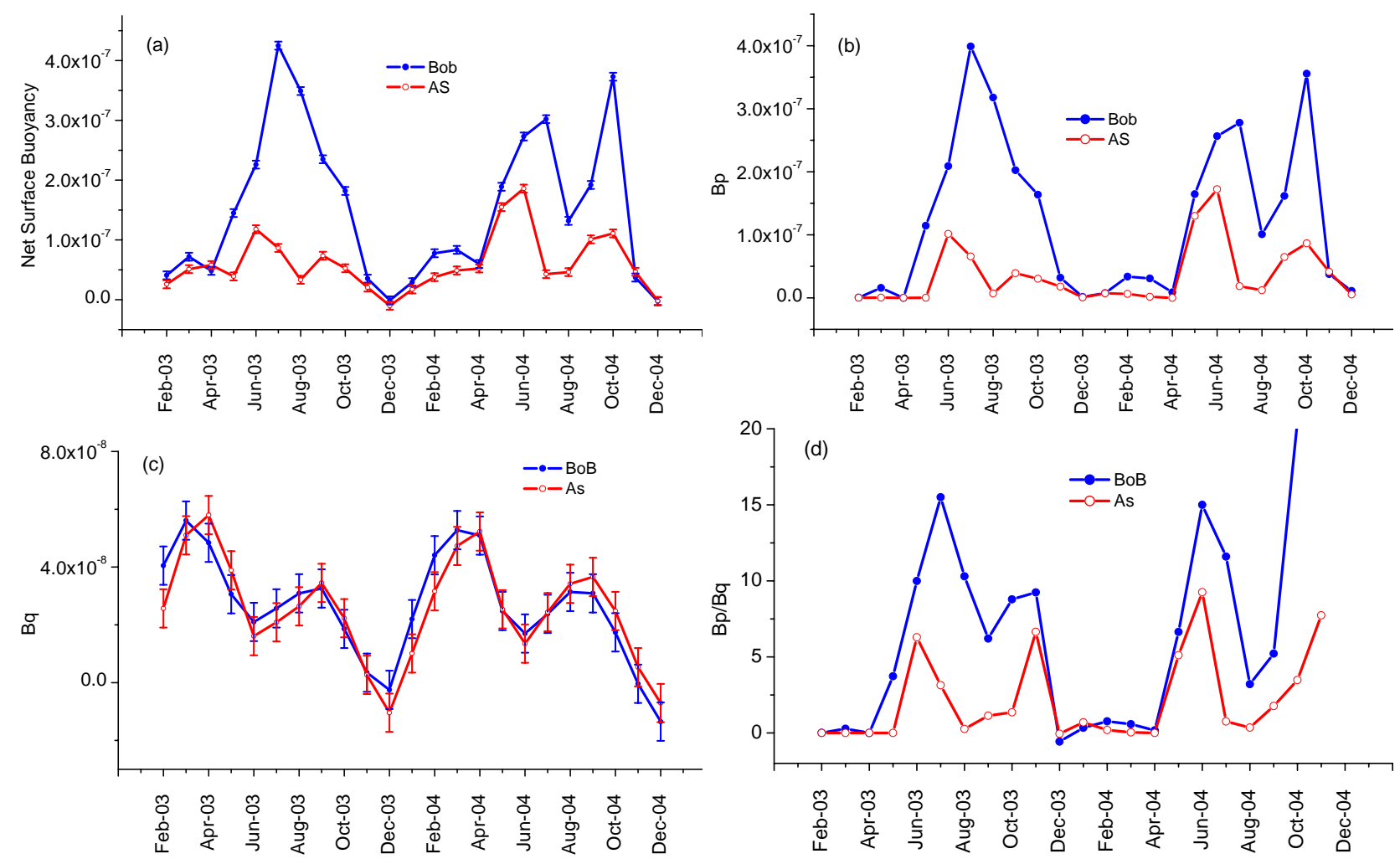

Fig. 2. Time Series of (a) net surface buoyancy with error bars (b) buoyancy due to fresh water $B_{p}$ (c) thermal buoyancy, $B_{q}$ with error bars and (d) ratio of fresh water to thermal buoyancy, $B_{p} / B_{q}$.

is that during September and October, added to the monsoon rains, the river influx makes the Bay even more fresh, whereas in AS, by this time, the monsoon starts receding and hence the surface buoyancy flux in BoB becomes very large and more stable compared to AS. This is a direct result from high amounts of precipitation as well as river inflow in BoB which is seen in buoyancy due to the fresh water flux $B p$ (Fig. 2b). During the other time of the year, the net surface buoyancy in both the basins is small and less than $1 \times 10^{-7} \mathrm{~m}^{2} / \mathrm{s}^{3}$.

In both AS and BoB the net buoyancy flux is dominated by that due to fresh water and hence the net buoyancy is an annual harmonic rather than semiannual, as in buoyancy due to the thermal component $B_{q}$ (Fig. 2c). The net buoyancy flux is more than three times during the summer monsoon compared to rest of the year (Fig. 2a). The surface buoyancy due to freshwater flux is more than double in BoB than in AS during the peak monsoon period (Fig. 2b). The ratio of fresh water buoyancy to thermal buoyancy (Fig. 2d) yields a value more than 10 and peaking to 15 in $\mathrm{BoB}$ in the summer monsoon months, whereas it is about 5 in June 2003 and 9 in June 2004 in AS, indicating that there is good amount of precipitation during 2004 compared to 2003. During the rest of the year the ratio is nearly one. The high ratio in $\mathrm{BoB}$ compared to AS and its prolonged nature itself is a measure of the freshwater.

\subsection{M-O Length and $L / h$}

The Monin-Obukhov length (M-O length, $L$ ) is the depth at which the wind generated turbulence is balanced by the buoyancy due to surface warming and freshening (salting) by precipitation (evaporation). In both BoB and AS, the M$\mathrm{O}$ length (Fig. 3d) exhibits a large negative peak during the summer monsoon months. In Bay of Bengal the M-O length during the summer monsoon ranges between $20 \mathrm{~m}-45 \mathrm{~m}$. These large values of M-O length during summer monsoon are due to large winds (friction velocity shown in Fig. 3a). $\mathrm{M}-\mathrm{O}$ length in AS is semiannual with large values during the summer monsoon, owing to high wind stress, whereas in $\mathrm{BoB}$ even though the winds are as high the net surface buoyancy is very large and this restricts M-O length to shallower depths. The large values of $L$ in AS during the summer monsoon range between $40 \mathrm{~m}-150 \mathrm{~m}$. These large values in AS during July-August are attributed to reduced buoyancy in AS compared to BoB, even though both the observational regions experience the same wind-stress (Fig. 3a).

During the winter monsoon months of November and January, the M-O length exhibits a negative peak. But during 

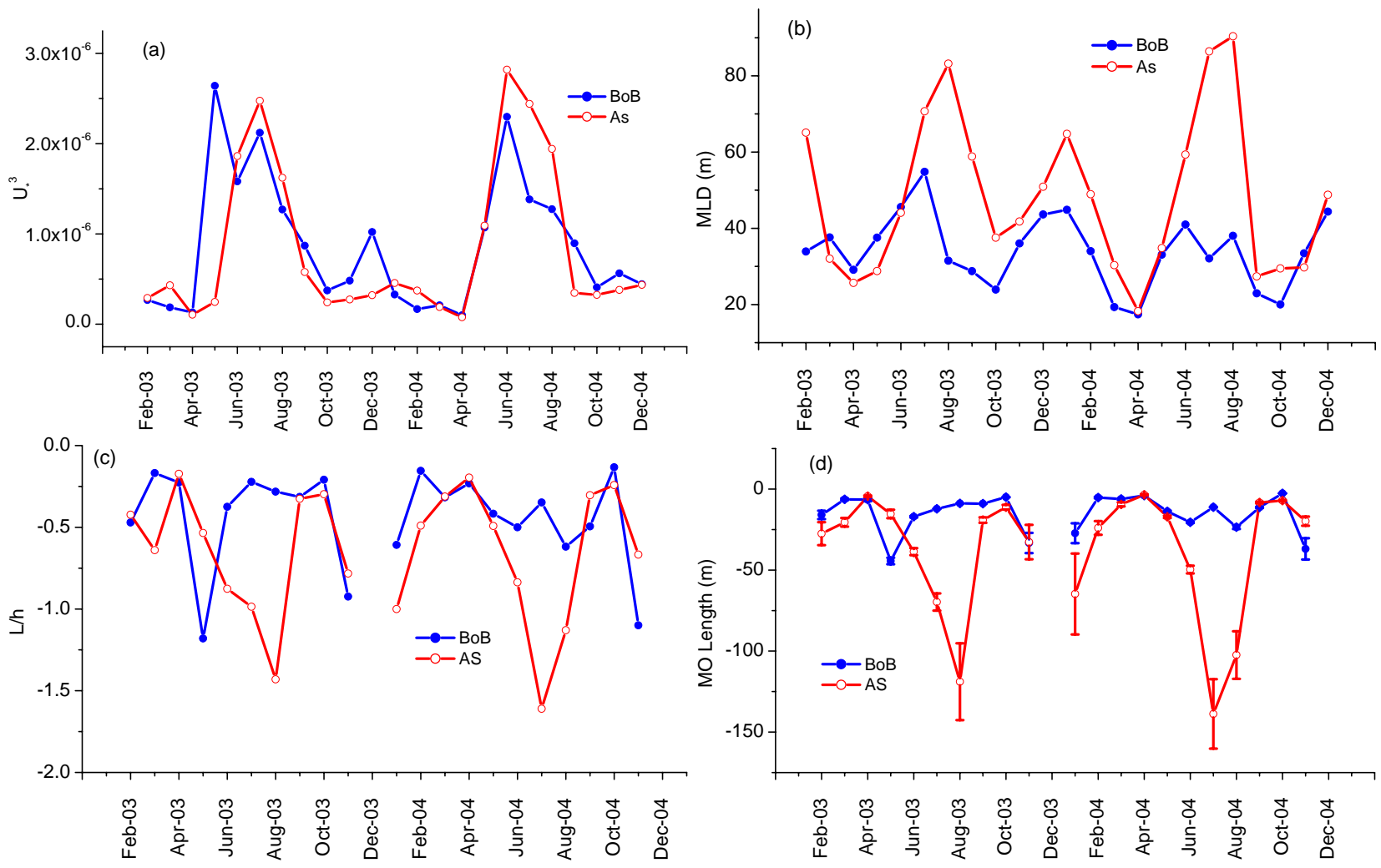

Fig. 3. Time Series of (a) ustar cubed (b) $\operatorname{MLD}(h)(\mathbf{c})$ ratio of M-O length to mixed layer depth $(L / h)(\mathbf{d})$ M-O length $(L)$ with error bars.
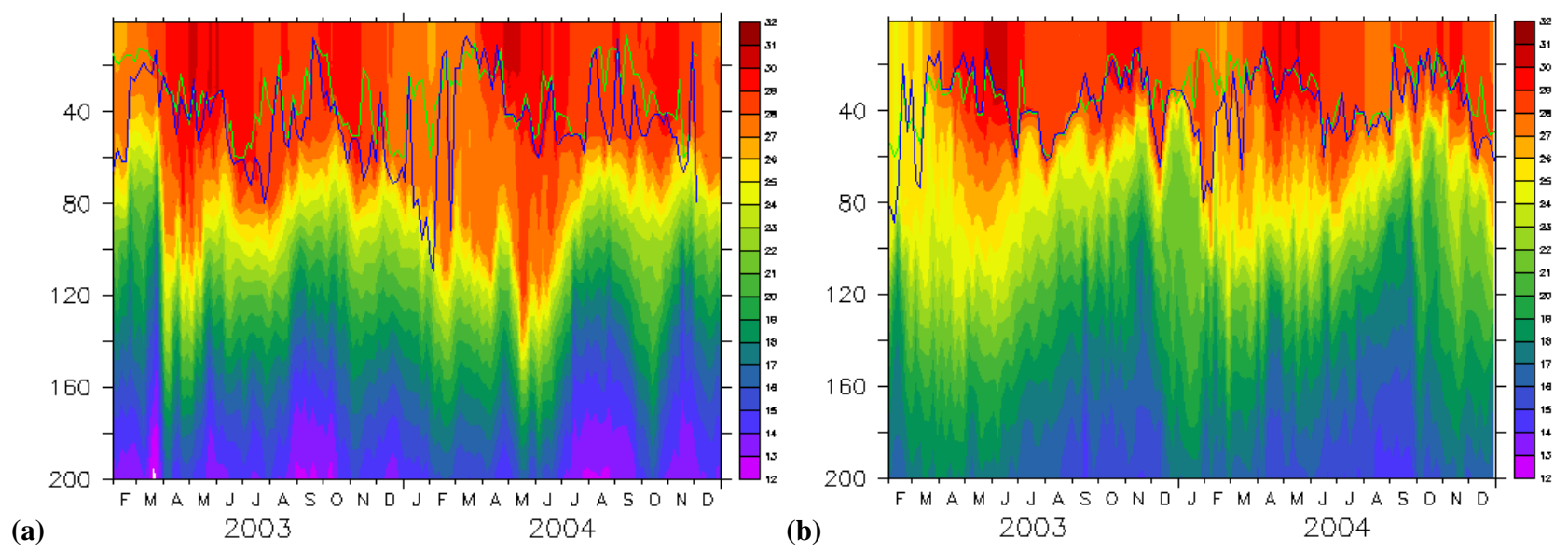

Fig. 4. Time depth series of temperature (a) BoB-2900093 (b) AS-2900090 with depth of the mixed layer (green) and depth of isothermal layer (blue) overlayed.

December the net heat flux in both the basins AS and BoB is out of the ocean and is negative. The net buoyancy flux is dominated by the thermal buoyancy during December and thus is resulting in a small negative net buoyancy. Hence a positive M-O length is observed in both the basins during December, indicating convective instability. This implies that the upper ocean is convectively unstable in December. However, the small magnitude of monthly averaged net negative buoyancy results in very high $L$ values, leading to large errors in magnitude ( $L$ and $L / h$ values for December are hence not shown). 
During the inter-monsoon periods of spring (March-April) and fall (September-October), the M-O length is very small in both AS and BoB. After the summer monsoon when the $\mathrm{M}-\mathrm{O}$ length reaches maximum depth, the fall season begins during which time the M-O length in BoB decreases from a maximum at $40-\mathrm{m}$ depth to less than $5 \mathrm{~m}$. In BoB, during the spring inter-monsoon (March-April) $L$ values of around $6 \mathrm{~m}-10 \mathrm{~m}$ due to very low winds (Fig. 3a) are observed. During this season the surface starts gaining buoyancy as the ocean starts gaining heat. Except in December when the net heat flux is negative, the M-O length is always negative in BoB for both 2003 and 2004. These negative values of $L$ imply that the ocean is always stable (except in December).

Both M-O length $L$ and $L / h$ are greater in AS than in BoB during the summer monsoon months. The changes in $L / h$ values (Fig. 3c) are much a reflection of those in MO length (Fig. 3d), despite the mixed layer depth $(h)$ in AS (Fig. 3b) being much larger than in the Bay of Bengal. This is due to the relative changes in surface buoyancy forcing and wind forcing. When $|L / h|>1$, the mixed layer is dominated by wind mixing. On the other hand, when $|L / h|<1$ wind energy available to mix is much less and could mix only a few top layers of the ocean, and the balance between thermal buoyancy and wind energy is achieved at a very small depth $L$. In the Arabian Sea the $L / h$ plot shows very large values during the summer monsoon months, during both the years, indicating a very highly wind dominated region. On the other hand, the $L / h$ values during the summer monsoon months of 2004 in Bay of Bengal (Fig. 3c) are less than one indicating that wind mixing is confined by buoyancy effects to some upper layers limited by $L$. However, during the inter-monsoons spring (March-April) and fall months (September-October), the $L / h$ values in both $\mathrm{BoB}$ and $\mathrm{AS}$ are small and negative, showing a dominancy of buoyancy gain where the ocean gains heat during spring and fall. During the spring period, the MLD starts shoaling, but MLD is greater than the M-O length and the depth of this remnant interfacial layer between the M-O length and MLD depends on the history of wind forcing and the rotation $U_{*} / f$ (Garwood, 1987; Alexander et al., 2000). Figure 4 shows the time depth sections of temperature with mixed layer depth and the depth of isothermal layer overlaid, obtained from one Argo float with WMO ID 2900093 in BoB (Fig. 4a) and one in AS (Fig. 4b) with WMO ID 2900090 for the two years 2003-2004. From this figure it is seen that the thermal penetration is much deeper during spring for both the floats and hence influences the depth of the mixed layer to become deeper.

When $L / h<0.5$ and positive, the mixed layer is dominated by convectively driven turbulence. Conversely, during the winter monsoon there are periods of large (negative during November and January and positive during December) values of $|L / h|$, indicating convective instability because of buoyancy loss as well as wind driven turbulence. This convective instability leads to a deeper mixed layer. During winter monsoon in both $\mathrm{BoB}$ and $\mathrm{AS}$ the $L / h$ values are similar.
These large values of $L / h$ indicate that both winds and buoyancy contribute towards increasing the mixed layer depth on a monthly scale.

\section{Summary}

In both $\mathrm{AS}$ and $\mathrm{BoB}$ the net buoyancy flux is dominated by the fresh water buoyancy flux and hence in both the basins the net buoyancy is an annual harmonic rather than semiannual, as in the buoyancy due to the thermal component. The surface buoyancy is very high in BoB compared to AS throughout the two years, indicating a very highly stable upper ocean in BoB compared to AS. The net surface buoyancy continues to be large during September and October in BoB, which is a manifestation of the fresh water content in Bay of Bengal. During spring and fall, light penetration and rotation effects modify the MLD below the wind mixed layer $L$. An improved understanding of the oceanic buoyancy field will improve our understanding and prediction of seasonal and interannual changes in oceanic circulation and the feedback between oceanic circulation and the climate.

Acknowledgements. We are thankful to Director, INCOIS, for his constant encouragement and support with the Argo programme. The authors are thankful to Remote Sensing Systems for providing Quickscat winds (www.ssmi.com) and to GPCP for providing the GPCP data set and to SOC for providing the heat flux climatology data set. The authors are also thankful to ARGO International Programme. The authors are thankful to the anonymous referee and the editor for useful comments and suggestions that helped us improve the manuscript.

Topical Editor S. Gulev thanks one anonymous referee for her/his help in evaluating this paper.

\section{References}

Alexander, M. A., Scott, J. D., and Deser, C.: Processes that influence sea surface temperature and ocean mixed layer depth variability in a coupled model, J. Geophys. Res., 105, 16 823-16842, 2000.

Argo Science Team: On the design and Implementation of Argo An initial Plan for a global array of Profiling Floats, ICPO Report No.21, GODAE Report No 5., 32pp, The GODAE International Project office, Melbourne, Australia, 1998.

Borkowski, M. R. and Goulet, J. R.: Comparison of methods for interpolating oceanographic data, Deep Sea Res. Oceanogr. Abstr., 18(2), 269-274, 1971.

Garwood Jr., R. W.: Unsteady shallowing mixed layer, Proceedings ‘Aha Huliko'a, Hawaiian Winter Workshop January 1987, Hawaii Inst. of Geophys. Special Publication, edited by: Muller, P. and Henderson, D., 119-129, 1987.

Josey, S. A., Kent, E. C., and Taylor, P. K.: New Insights into the ocean heat budget closure problem from analysis of the SOC airsea flux climatology, J. Climate, 12(9), 2856-2880, 1999.

Prasad, T. G.: A comparison of mixed-layer dynamics between the Arabian Sea and Bay of Bengal: One-dimensional model results, J. Geophys. Res., C03035, doi:10.1029/2003JC002000, 2004. 
Ravichandran, M., Vinayachandran, P. N., Sudhir, J., and Radhakrishnan, K.: Results from the first Argo float deployed by India, Current Sci., 86(5), 651-659, 2004.

Shenoi, S. S. C., Shankar, D., and Shetye, S. R.: Differences in heat budgets of the near surface Arabian Sea and Bay of Bengal: Implications for the summer monsoon, J. Geophys. Res., 107(C6), 3052, doi:10.1029/2000JC000679, 2002.
Weller, R. A., Fischer, A. S., Rudnick, D. L., Eriksen, C. C., Dickey, T. D., Marra, J., Fox, C., and Leben, R.: Moored observations of upper-ocean response to the monsoons in the Arabian Sea during 1994-1995, DSR II., 49, 2195-2230, 2002. 